\title{
Eletrônica básica utilizando a metodologia da Blended Learning
}

\author{
Alexandro Lima Gomes, \\ Eduardo Tocchetto de Oliveira Júnior, \\ Francielli Freitas Moro, \\ Lucyene Lopes da Silva
}

\section{INTRODUÇão}

$\mathrm{O}$ uso de recursos tecnológicos dentro do contexto educacional, mais especificamente no ensino e aprendizagem, vem gradativamente crescendo e transformando o ambiente escolar. De acordo com Miyamoto (2017, p. 497), “o uso de tecnologias promove um efeito diferenciado no processo de ensino-aprendizagem, uma vez que esses instrumentos facilitam o acesso de todos os alunos ao conteúdo estudado". Aplicações focadas ao ambiente educacional vêm recebendo maior atenção e gradativamente o desenvolvimento de aplicações que agregam cada vez mais a consolidação de novos conceitos computacionais vêm crescendo.

Os educadores, por sua vez, precisam se adaptar a essa realidade e buscar meios para conduzir o conhecimento com o uso dos aplicativos ou ferramentas on-line na sala de aula, criando atividades que facilitem a vida profissional e social dos alunos. Eles precisam aperfeiçoar-se e aprender o melhor caminho de adaptar as ferramentas tecnológica ao conteúdo. Para Silva, Menezes e Fagundes (2016), com a inserção de tecnologia nas escolas, o professor deve participar de forma ativa do processo de construção do conhecimento do aluno, passando de transmissor do conhecimento a mediador, motivador e orientador da aprendizagem, permitindo-se interagir entre áreas e conteúdo, em busca de interdisciplinaridade. Barbosa (2005) diz que é necessário adaptar-se ao que é novo, mesmo sendo difícil perder velhos hábitos e paradigmas antigos dentro do contexto escolar. Beira e Nakamoto (2016) afirmam que o uso de ferramentas tecnológicas na educação pode ter vários benefícios, mas para que isso ocorra é necessário considerar uma capacitação intensiva e apoio por parte dos desenvolvedores aos professores na utilização das ferramentas, buscando práticas educativas inovadoras.

Outro ponto a ser destacado se reflete diretamente no aluno do século XXI, 
que nasceu em uma geração conectada e, consequentemente, vai para sala de aula com um perfil carregado de informações. A partir disso, surge um desafio aos professores, saber integrar o ensino com essa geração conectada.

Nesse artigo, foi realizada uma pesquisa bibliográfica em torno de ambientes de aprendizagem e da metodologia blended learning, que mistura atividade presenciais com atividades on-line, caracterizando-as e levando em consideração seus propósitos em ambiente educacional. Com isso, foi elaborada uma proposta de curso utilizando o Modular Object-Oriented Dynamic Learning Environment (MOODLE), para a aplicação em uma turma no curso de Eletrônica Básica, sendo nos tópicos 3, 4 e 5 apresentados a problemática, o planejamento e o desenvolvimento do curso, respectivamente.

\section{REFERENCIAL TEÓRICO}

Neste tópico, apresenta-se o que é blended learning e como a educação a distância tem contribuído de forma prática no processo de ensino e aprendizado a partir de Ambiente Virtual de Aprendizagem (AVA).

\subsection{BLENDED LEARNING}

O blended learning (b-learning), conhecido no Brasil como ensino híbrido, é uma forma de extensão da sala de aula presencial, o qual utiliza as Tecnologias de Informação e Comunicação (TIC) como canal de comunicação. Valente (2014) define o ensino híbrido como uma nova forma de ensino que mescla momentos em que o aluno estuda determinados conteúdos de forma on-line e outros em que o ensino ocorre em sala de aula, proporcionando a interação de alunos e professores. O professor deixa de ser transmissor do conhecimento passando a ser mediador, considerando as características dos seus alunos. Moskal, Dziubam e Hartman (2012) afirmam que o blended learning integra a educação tradicional simultaneamente encorajando o uso de plataformas de aprendizado on-line.

Pode-se imaginar que a forma de ensino baseado no blended learning tenha surgido há pouco tempo, por meio de tecnologias recentes, como os tablets e os smartphones, por exemplo, mas aí reside um engano. No Brasil esse conceito já estava presente, por exemplo, nos projetos de educação a distância com a veiculação de programas na Rádio Nacional do Rio de Janeiro, nas décadas de 1940 e 1950 e em 1970, com a criação do Projeto Minerva, que combinava material didático impresso com a transmissão de programação oficial educativa pela Rádio MEC, visando a suprir carências daqueles que não tinham concluído a esco- 
la básica. Araújo e Panerai (2012) trazem que, a partir da portaria n 2.253/2001, a qual permite às instituições o direcionamento de $20 \%$ de sua carga horária à inclusão de atividades não presenciais, o blended learning ganha novo impulso no país.

Como mostra a Figura 1, o ensino tradicional é caracterizado por Rovai e Jordan (2004) pela motivação oferecida pelo professor sobre o conteúdo ensinado, a personalização, o feedback constante, a fluência na explicação, a relevância do conteúdo e, principalmente, a interação entre os alunos. O modelo híbrido busca mesclar tudo isso, com as características apresentadas no ensino a distância, como a mobilidade, a otimização do conteúdo, o gerenciamento e o controle, a autonomia do aluno, a redução de custos e o alcance.

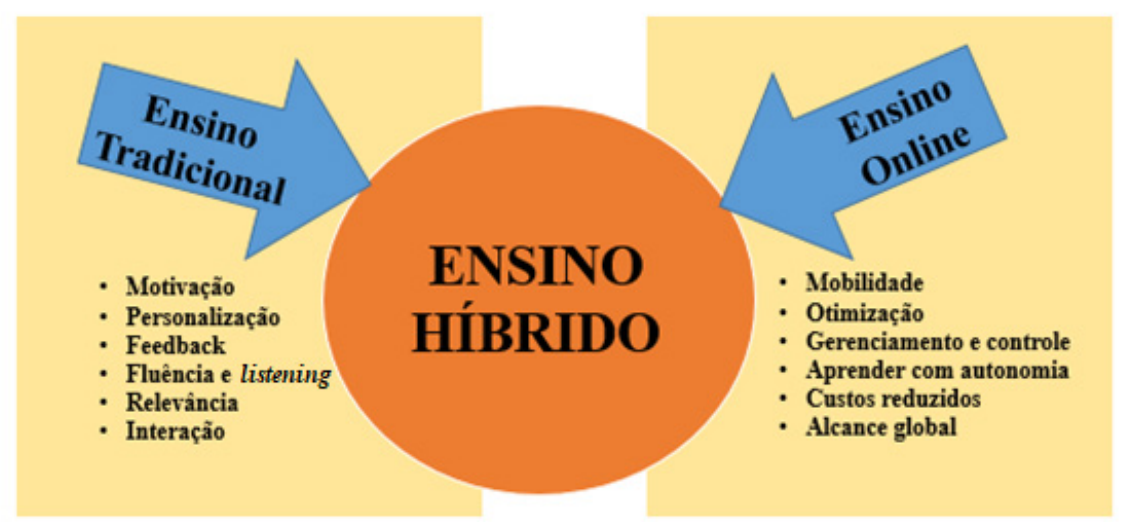

Figura 1: Ensino híbrido.

Fonte: Autores (2017).

O ensino caracterizado como blended learning confere ao aluno maior autonomia, permitindo a ele produções autorais, socialização de saberes e flexibilidade de estudos (local e temporal). Passam-se a ser usadas ferramentas como os ambientes virtuais de aprendizado, documentos compartilhados, redes sociais, tecnologias mobile, entre outros, configurando espaços de trocas significativas e construção interativa e colaborativa do saber. Segundo Grahan, Woodfield e Harrison (2012), os maiores benefícios do ensino híbrido são a facilidade no acesso, a flexibilidade e a eficiência na transmissão de conhecimento. Para eles, é necessário pensar no aprendizado considerando três categorias principais: a estratégia (as definições da BL, objetivos, planejamento, entre outros), a estrutura (aqui se enquadra tanto a estrutura física como a tecnológica) e o suporte (técnico e pedagógico, abordando a capacitação docente). 
Staker e Horn (apud Valente, 2014) ainda caracteriza quatro modelos dessa metodologia de ensino:

1) Flex: o foco no processo de aprendizagem é o conteúdo que o aluno trabalha on-line, com suporte seja de um professor ou de um tutor;

2) Blended misturado: o aluno realiza uma ou mais disciplinas (ou conteúdo) de forma totalmente on-line, a fim de complementar as presenciais;

3) Virtual enriquecido: a ênfase maior é nas disciplinas on-line, sendo que ele pode realizar algumas atividade presenciais, como experiências práticas, laboratórios, entre outros.

4) Rodízio: o aluno pode circular por diferentes tipos de aprendizagem, dentre eles, rodízio entre estações de trabalho, rodízio entre laboratórios, rodízio entre várias modalidades de acordo com os horários, ou a sala de aula invertida, onde o aluno aprende o conteúdo antes de frequentar a sala de aula, que passa a ser o local para discussão.

Neste trabalho explorou-se o blended misturado, pois os alunos exploraram o conteúdo de Eletrônica Básica baseado nas orientações do professor, como forma a complementar um conteúdo já apresentado em sala de aula.

\subsection{AMBIENTES VIRTUAIS E A METODOLOGIA BLENDED LEARNING}

Ambientes Virtuais de Aprendizagem (AVA) são sistemas que permitem a elaboração do ensino de forma não presencial, auxiliando alunos e professores no processo da difusão do conhecimento. A partir da formação desses ambientes, houve uma variação do termo, que ficou conhecido como Ambiente Virtual de Ensino e Aprendizagem, que, segundo Grossi, Moraes e Brescia (2013), foca o planejamento, a implementação e avaliação dos professores em relação às atividades didáticas do ambiente, mesclando mídias e recursos e apresentando as informações de uma forma mais organizada e interativa. Scutaru et al. (2009) colocam que os AVA tornam a educação mais flexível, porque o aluno pode acessar seus materiais onde, quando e como quiser, fazendo dos professores organizadores da atividade de aprendizagem e facilitadores da autonomia dos alunos.

Além desses ambientes, outras ferramentas como: redes sociais, aplicativos e jogos digitais podem ser utilizadas no processo de ensino. $\mathrm{O}$ foco são os ambientes virtuais, para auxiliar na blended learning. Araújo e Panerai (2012) utilizaram as ferramentas MOODLE e Facebook, e, segundo as autoras, a proposta metodológica tinha como objetivo:

O desenvolvimento de um diálogo permanente com os discentes, indo e vindo do presencial ao virtual, com atividades realizadas tanto em sala de 
aula como aulas substituídas por debates via fórum de discussão, chats e atividades de pesquisa e compartilhamento (ARAÚJO; PANERAI, 2012, p. $6)$.

Outro exemplo de aplicação foi a implementação do blended learning no trabalho de Gomes e Melo (2013), em um minicurso "Lógica de Programação com App Inventor for Android". Foi realizado em uma escola da rede pública estadual para estudantes do Ensino Médio e objetivou-se promover um cenário mais flexível, bem como a apresentação dos conteúdos de uma maneira mais atraente e lúdica.

Na mesma linha, Silva, Gomes e Brito (2013) citam a prática executada na Universidade Federal do Vale do São Francisco, na disciplina de Resistência dos Materiais, tendo a Teoria da Atividade de Engestrom como base, relatada no artigo Estratégias para Blended Learning.

\section{PROBLEMA E METOdOLOGIA}

O uso da tecnologia, principalmente da internet e de dispositivos móveis, vem contribuindo para o acesso de materiais, conteúdos digitais e mídias que auxiliam no processo de ensino e aprendizagem. Então, a questão principal é pensar em como apresentar o conteúdo através das tecnologias a fim de facilitar a integração dos alunos.

O problema da pesquisa é a construção de um curso de Eletrônica Básica baseada na estratégia de blended learning e voltada para alunos do curso técnico subsequente (cursado após a conclusão do Ensino Médio) em Eletromecânica, na disciplina de Eletrônica Analógica do Instituto Federal de Santa Catarina (IFSC), campus Araranguá.

Atualmente, a metodologia utilizada para a disciplina de Eletrônica Analógica é a expositiva com aulas teóricas e algumas aulas práticas. A turma é composta por 16 alunos, divididos em duplas. As aulas são aplicadas no laboratório de eletrônica, que é formado por bancadas, e nelas os instrumentos são postos para o uso em aulas práticas. Esperou-se que, com a aplicação da estratégia de blended learning, houvesse um acréscimo de tempo para as atividades práticas desenvolvidas, tanto em laboratórios remotos como no laboratório de eletrônica, do campus Araranguá. No modelo atual há uma demanda grande para a utilização das aulas para a exposição dos conteúdos necessários à disciplina. 


\section{FERRAMENTA UTILIZADA}

A Internet é uma fonte inesgotável de conteúdo, mas que se caracteriza por apresentá-los de forma dispersa. Faz-se necessário, assim, construir uma ferramenta de coesão que disponibilize esses materiais de forma organizada, que faça a ligação entre o professor e o aluno, tendo como base as Tecnologias de Informação e Comunicação (TIC).

Para a construção do curso proposto, considerando a ideia do blended learning, foi utilizada a plataforma MOODLE, a fim de disponibilizar ao aluno métodos diferenciados de ensino, não se restringindo apenas em estabelecer um mero repositório de material de aula, considerando que serão ministradas aulas presenciais e à distância.

O MOODLE é um Sistema de Gerenciamento de Cursos (SGC) desenvolvido para apoiar o processo de ensino e aprendizagem, bem como a gestão desses recursos voltados à criação, ao armazenamento, ao gerenciamento e à distribuição de conteúdo, além de recursos para comunicação e desenvolvimento de atividades colaborativas (ROSA, 2017). Uma das características do MOODLE é o forte componente de participação, comunicação e colaboração entre aluno-professor e aluno-aluno, além de permitir que o aluno possa aprender a aprender, de maneira autônoma e com independência tempo-espaço.

\section{DESENVOLVIMENTO DO CURSO EM ELETRÔNICA BÁSICA}

O curso em de Eletrônica Básica foi construído utilizando-se a plataforma MOODLE do Laboratório de Mídia e Conhecimento (LabMídia) da Universidade Federal de Santa Catarina (UFSC). O acesso ao MOODLE possibilitou dimensionar o curso e, modularmente, agregar material de apoio (textos e vídeos), atividades práticas (simulações on-line e laboratórios virtuais) e atividades avaliativas (questionários, fóruns etc.).

Para uma melhor organização do curso, este foi dividido em 20 aulas, estabelecendo-se, assim, um cronograma da disciplina de Eletrônica, baseado no cronograma da disciplina de Eletrônica Analógica do curso técnico em Eletromecânica integrado para Ensino Médio do Instituto Federal de Santa Catarina, campus Araranguá. Cada aula refere-se a uma semana do cronograma da disciplina de Eletrônica Analógica do curso de Eletromecânica, assim, o aluno tem à sua disposição todo o material, desde o início do curso, podendo com ele interagir a todo momento. A página do curso é caracterizada na Figura 2. 


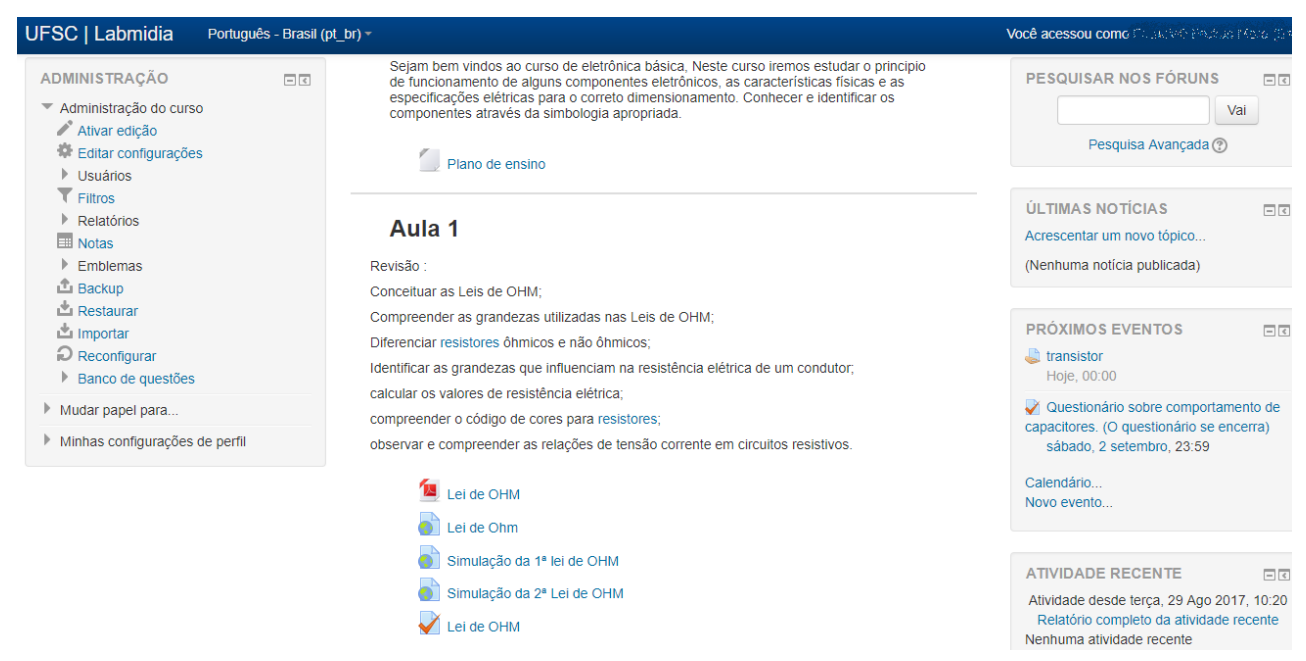

Figura 2: Página inicial do curso.

Fonte: Autores (2017).

A seguir, estão caracterizados os tipos de materiais disponibilizados no curso Eletrônica Básica, são eles:

a) Materiais de apoio: neste quesito, estão reunidos notas de aula, leituras complementares e artigos sugeridos para aprofundamento dos estudos. Dessa forma, a plataforma funciona como uma espécie de repositório digital, permitindo o acesso ao aluno a todo momento que sentir necessidade, tendo-se o cuidado de que os arquivos digitais estejam em uma extensão que permita a leitura em qualquer dispositivo (notebook, tablets, smartphone etc.).

b) Vídeos: o uso de vídeos para fins de ilustração do conhecimento adquirido e para um complemento de aprendizado não é novidade. O que é recente é a quantidade de produção audiovisual que nos é disponibilizada a cada instante, através das TIC. Diariamente, são produzidos milhares de vídeos, e a filtragem por parte do docente deste apanhado pode configurar uma fonte importante de recursos didáticos. Para Morán (1995), esse é um fator importante, pois, ao se usar o vídeo em sala de aula, na cabeça dos alunos, significa lazer e não aula. $\mathrm{O}$ mesmo autor ainda afirma que isso, quando usado corretamente, atrai o aluno para os assuntos do planejamento pedagógico. E essa sala de aula tanto pode ser real ou virtual. A Figura 3 apresenta um exemplo de vídeo inserido ao curso do ambiente no MOODLE. 


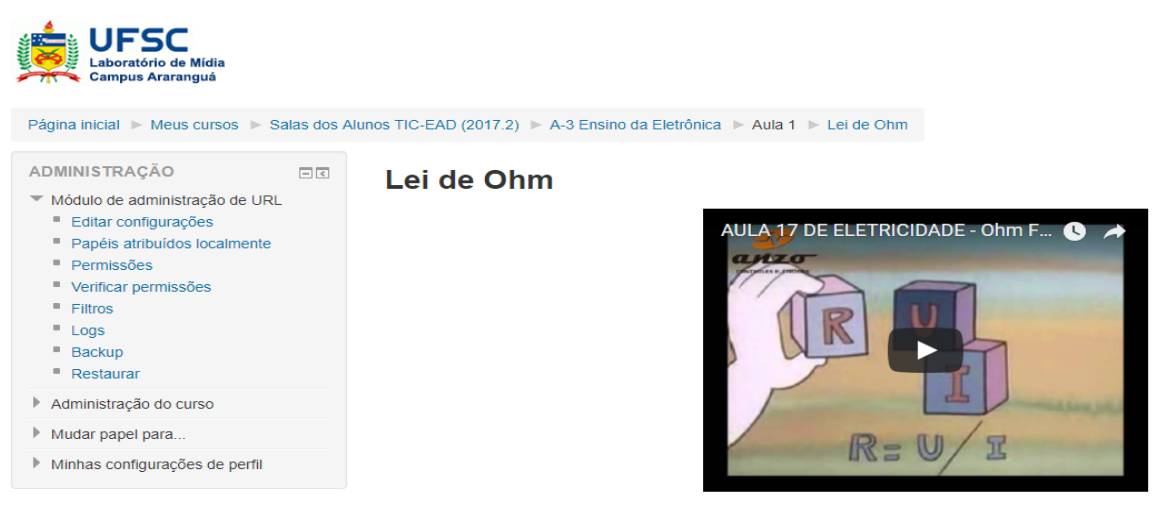

Figura 3: Vídeo inserido no ambiente do curso.

Fonte: os autores, 2017.

A fonte dos vídeos é o YouTube, devido à sua popularização e fácil acesso. Pellegrini et al. (2010) o definem como um serviço on-line de vídeos que permite a seus usuários carregar, compartilhar, produzir e publicar vídeos de forma digital, podendo participar de comunidades e canais.

Cabe ao professor pesquisar, selecionar e assistir aos vídeos para verificar sua correção e o potencial de aprendizado que possuem para depois disponibilizar aos alunos. No MOODLE, é possível apresentar o link (endereço eletrônico) do vídeo ou incorporá-lo aos tópicos.

c) Simulações: as simulações são importantes recursos suplementares ao processo ensino-aprendizagem, pois podem ser utilizadas em diversas situações, em vários meios físicos e virtuais, de fácil acesso e portabilidade (MACÊDO; DICKMAN; ANDRADE, 2012). De acordo com Coelho (2002), as simulações podem ser interativas e não-interativas; em uma simulação interativa, o usuário pode alterar vários parâmetros da simulação, explorando a situação física representada, verificando as implicações das alterações feitas no comportamento do fenômeno estudado, sendo que em uma simulação não interativa, apenas é apresentado ao usuário a evolução de algum parâmetro ao longo do tempo.

As simulações utilizadas no curso de Eletrônica Básica são oriundas do Physics Education Technology (PhET) da University of Colorado Boulder, que desenvolve uma série de simulações interativas nas áreas de Física, Química, Biologia, Ciências da Terra e Matemática, disponíveis em vários idiomas (inclusive português) e abertas à comunidade escolar. 
Especificamente nesta proposta foram utilizadas as simulações referentes à $1^{a}$ Lei de Ohm, que relaciona a tensão, a resistência e corrente elétricas, e a $2^{\mathrm{a}}$ Lei de $\mathrm{Ohm}$, que relaciona a resistência, as dimensões do condutor elétrico (comprimento e a área da secção reta) e a resistividade do material. Um exemplo de simulação no curso é mostrado na Figura 4.

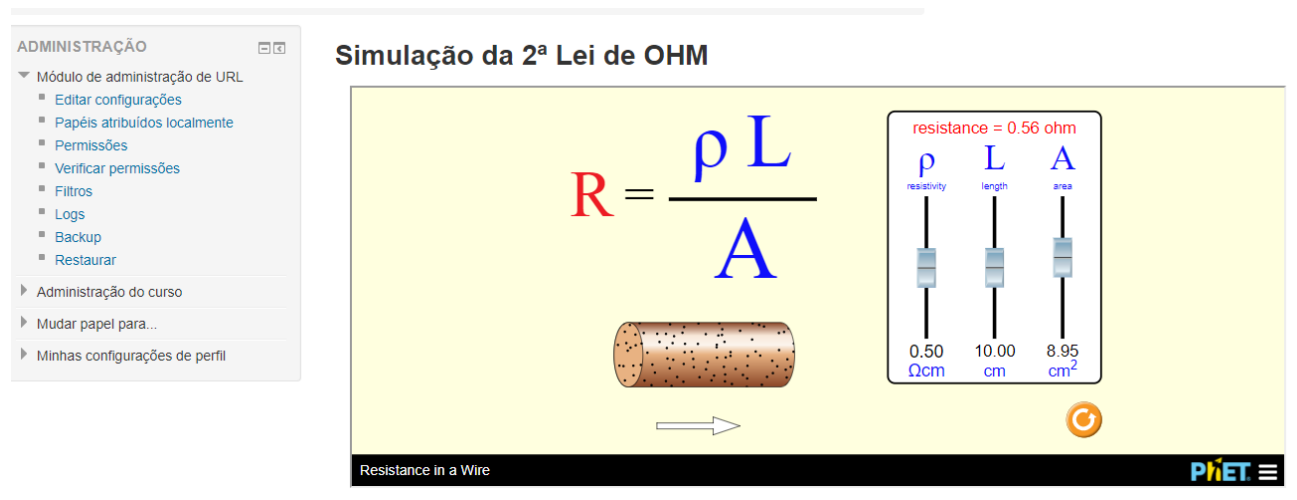

Figura 4: Simulação da 2a Lei de OHM no curso.

Fonte: Autores (2017).

d) Laboratórios remotos: os laboratórios remotos constituem uma recente forma de ensino, cuja principal característica é a disponibilidade e a acessibilidade, o que nem sempre é visto em um laboratório real. Segundo Silva (2006, p. 124), define-se experimentação remota como:

O emprego dos recursos e tecnologias oferecidos pela WWW para a interação com ferramentas de experimentação remota localizada tanto no cliente como no servidor, recorrendo aos navegadores WWW como suporte para interfaces gráficas entre os usuários e os experimentos (SILVA, 2006, p. 124).

Caracteriza-se um laboratório remoto, conforme Fidalgo et al. (2013), pela separação espacial entre o experimento real e o observador, cuja interatividade depende de um meio de comunicação (Internet), com uma interface própria para isto.

As vantagens dessas modalidades experimentais, segundo Heradio et al. (2016), não só permitem redução de custos, mas eles oferecem outros benefícios importantes:

1. Disponibilidade: Virtual and Remote Laboratories (VRL) podem ser usados a partir de qualquer lugar a qualquer momento, assim, eles podem apoiar os alunos geograficamente separados, que além disso estão condicionados a diferentes fusos horários. 2. A acessibilidade para pessoas com deficiência. 3. Visibi- 
lidade: sessões de laboratório podem ser vistas por muitas pessoas ou mesmo gravadas. 4. Segurança: VRL pode ser uma alternativa melhor para laboratórios práticos para a experimentação perigosa (HERADIO et al., 2016, p.2).

Neste curso, o experimento remoto elencado foi "Módulos Educacionais para Teoria e Prática de Circuitos Elétricos e Eletrônicos”, produzido e mantido pelo projeto Virtual Instrument Systems In Reality (VISIR), do Laboratório de Experimentação Remota (RExLab), do campus Araranguá da Universidade Federal de Santa Catarina. Este experimento, de acordo com Fidalgo (2013, p. 135):

Permite que professores e alunos realizem experiências remotamente e em tempo real, com componentes e equipamentos de teste e medição reais (fonte de alimentação tripla direct current-DC, gerador de funções, multímetro e osciloscópio), com os quais é possível interagir via painéis frontais virtuais, disponibilizados no computador do utilizador. A placa de montagem é substituída por uma matriz de comutação, onde os componentes necessários estão fisicamente instalados. Os professores e alunos usam uma placa de montagem virtual para criar cada circuito, ou seja, para configurar os relés das conexões da matriz e os componentes instalados de forma a montar o circuito pretendido. A matriz é constituída por uma coluna de placas, que incluem também bases de componentes ou conectores para instrumentos em cada placa. Assim, o número de componentes em utilização depende do número de placas disponíveis na matriz (FIDALGO, 2013, p. 135).

e) Atividades avaliativas: a plataforma MOODLE apresenta uma diversificada forma de promover a avaliação de um aluno, seja pelo número de acessos aos materiais, pela participação no envio de respostas ou produções textuais, bem como com avaliações on-line, na forma de enquetes, questionários de múltipla escolha, dissertativos etc., com grande variedade de formatos (SABBATINI, 2007). Neste curso proposto para o ensino de Eletrônica Básica, foram selecionadas as modalidades: fórum, questionários (discursivos e de múltipla escolha), quizz e a produção audiovisual de um determinado experimento.

f) Fóruns: consistem em um local de discussão sobre diversos aspectos dos conteúdos trabalhados no MOODLE. Como característica importante, ressalta-se a participação ativa dos alunos e a interação com um moderador, podendo ser um tutor ou o próprio docente. Os fóruns também podem ter a função de mural de recados, permitindo a inclusão de anexos. Com as publicações dos alunos, o professor tem mais uma forma de diagnosticar possíveis dificuldades de aprendizado e em que pontos a discussão deve ser retomada. 


\section{CONSIDERAÇÕES FINAIS}

O uso de mídias diferentes aproximam os alunos dos processos educacionais, tornando o material disponível para os discentes a qualquer momento através do MOODLE, bastando utilizar um computador pessoal (pc), ou um smartphone.

O MOODLE possibilita aos estudantes ações interativas com os materiais disponibilizados, trabalhando o conteúdo de formas diferentes, com o intuito de torná-los mais atraentes, e concentrando-os em um local de fácil acesso para os alunos.

O blended learning é uma metodologia de ensino que usa os dois mundos e possui atividades presenciais - o curso desenvolvido neste artigo é parte do curso técnico em Eletromecânica - e atividades a distância. Esse conceito de ensino busca tornar as aulas mais dinâmicas e atraentes para os alunos.

Nas atividades a distância, destaca-se o uso de simuladores e experimentos remotos que ajudam os alunos na utilização dos equipamentos reais com maior segurança, pois esses experimentos não oferecem riscos de danos aos equipamentos e componentes do laboratório. O fórum é outra ferramenta importante para a socialização do conhecimento e interação professor-aluno e aluno-aluno. Todos esses procedimentos do Ensino a Distância contribuem para o desenvolvimento das atividades presenciais, aumentando a segurança dos alunos ao interagirem com equipamento do laboratório.

\section{REFERÊNCIAS}

ARAÚJO, R.; PANERAI, T. Relato de experiência de blended learning: o MOODLE e o Facebook como ambientes de extensão da sala de aula presencial. In: CONGRESSO BRASILEIRO DE INFORMÁTICA. WORKSHOP DE INFORMÁTICA NA ESCOLA, 18., 2012, Rio de Janeiro, Anais... Rio de Janeiro: UFRJ, 2012. v. 1, n. 1.

BARBOSA, R. M. (Org.). Ambientes Virtuais de Aprendizagem. Porto Alegre: Artmed, 2005.

BEIRA, D. G.; NAKAMOTO, P. T. A formação docente inicial e continuada prepara os professores para o uso das Tecnologias de Informação e Comunicação (TICs) em sala de aula? In: CONGRESSO BRASILEIRO DE INFORMÁTICA NA EDUCAÇÃO (CBIE2016), 5.; WORKSHOP EM INFORMÁTICA NA EDUCAÇÃO (WIE), 22., 2016, Uberlândia. Anais... Uberlândia: UFU, 2016. p. 825-834.

COELHO, R. O. O uso da informática no ensino de física de nível médio. 2002. Dissertação (Mestrado em Educação) - Faculdade de Educação, Universidade Federal de Pelotas, Pelotas, 2002.

FIDALGO, A. V. da S. et al. Adaptação de laboratórios remotos a cenários de ensino: 
casos de estudo com VISIR e RemotElectLab. VAEP-RITA, v. 1, n. 2, p. 135-141, 2013.

GOMES, T. C. S.; MELO, J. C. B. de. O Pensamento computacional no Ensino Médio: uma abordagem blended-learning. In: WORKSHOP SOBRE EDUCAÇÃO EM COMPUTAÇÃO, 21.; CONGRESSO DA SOCIEDADE BRASILEIRA DE COMPUTAÇÃO, 33., 2013, Maceió. Anais... Belo Horizonte: UFMG, 2013. p. 651-660.

GRAHAM, C. R.; WOODFIELD, W.; HARISON, J. B. A framework for institutional adoption and implementation of blended learning in higher education. Internet and higher education. 25 set. 2012. Florida: Elsevier, 2012. p. 4-14.

GROSSI, M. G. R.; MORAES, A. L.; BRESCIA, A. T. Interatividade em ambientes virtuais de aprendizagem no processo de ensino e aprendizagem na Educação a Distância. @rquivo Brasileiro de Educação, Belo Horizonte, v. 1, n. 1, p. 75-92, 2013. Disponível em: <http://periodicos.pucminas.br/index.php/arquivobrasileiroeducacao/ article/view/ P.2318-7344.2013v1n1p75/5543>. Acesso em: 13 ago. 2017.

HERADIO, R. et al. Virtual and remote labs in education: a bibliometric analysis. Computers \& Education, p. 14-38, 2016. Disponível em: <https://www.tib.eu/en/search/ id/BLSE\%3Avdc_100031632689.0x000001/Virtual-and-remote-labs-in-education-A-bibliometric/>. Acesso em: 13 ago. 2017. DOI: 10.1016/j.compedu.2016.03.010.

MACÊDO, J. A. de; DICKMAN, A. G.; ANDRADE, I. S. F de. Simulações computacionais como ferramentas para o ensino de conceitos básicos de Eletricidade. Caderno Brasileiro de Ensino de Física, Florianópolis, p. 562-613, ago. 2012. ISSN 2175 7941. Disponível em: <https://periodicos.ufsc.br/index.php/fisica/article/view/2175-7941.2012v29nesp1p56 2>. Acesso em: 5 maio 2018. DOI: <https://doi. org/10.5007/2175-7941.2012v>.

MIYAMOTO, M. R. T. O impacto do uso das novas tecnologias em aulas de inglês para curso tecnológicos. Revista CBTecLE, São Paulo, v. 1, n. 1, p. 494-507, 2017.

MORÁN, J. M. O vídeo na sala de aula. Comunicação \& Educação, São Paulo, n. 2, p. 27-35, abr. 1995. ISSN 2316-9125. Disponível em: <http://www.revistas.usp.br/comueduc/article/view/36131>. Acesso em: 13 ago. 2017. DOI: <http://dx.doi. org/10.11606/issn.2316-9125.v0i2p27-35>.

MOSKAL, P.; DZIUBAN, C.; HARTMAN, J. Blended learning: a dangerous idea? Internet and higher education, Florida: Elsevier, p. 15-23, 20 dez. 2012.

PELLEGRINI, D. P. et al. YouTube. Uma nova fonte de discursos. Biblioteca online de Ciências da Comunicação. Universidade da Beira Interior, 2010. Disponível em:<http:// www. bocc. ubi. pt/ boccmirror/pag/bocc-pelegrini-cibercultura. pdf $>$. Acesso em 13 ago. 2017.

ROSA, A. M. O uso da tecnologia da informação em sala de aula como fator mediador do trabalho do professor de história: a utilização da plataforma MOODLE. 2017. Dissertação (Mestrado em História) - Regional Catalão, Universidade Federal de Goiás, Catalão, 2017.

ROVAI, A. P.; JORDAN, H. M. Blended learning and sense of community: a compara- 
tive analysis with traditional and fully online graduate courses. International Review of Research in Open and Distance Learning, Virgínia, v. 5, n. 2, ago. 2004. ISSN 1492-3831. Disponível em: <http://www.irrodl.org/index.php/irrodl/article/ view/192>. Acesso em: 13 de ago. 2017. DOI: <http://dx.doi.org/10.19173/irrodl. v5i2.192>.

SABBATINI, R. M. E. Ambiente de Ensino e Aprendizagem via internet: a plataforma MOODLE. O que é o MOODLE. Instituto EduMed, p. 1-7, 2007. Disponível em: $<$ http://www.ead.edumed.org.br/file.php/1/PlataformaMOODLE.pdf >. Acesso em: 13 ago. 2017.

SCUTARU, G. et al. Enhanced Individualized learning environment's impact on the learning process. In: IEEE INTERNATIONAL CONFERENCE ON E-LEARNING IN INDUSTRIAL ELECTRONICS (ICELIE 2009), 3. Anais... Porto: IEEE, 2009. p. 51-56.

SILVA, J. B. A utilização da experimentação remota como suporte para ambientes colaborativos de aprendizagem. 2006. Tese (Doutorado em Engenharia e Gestão do Conhecimento). Departamento de Engenharia e Gestão do Conhecimento, Universidade Federal de Santa Catarina, Florianópolis, 2006.

SILVA, J. C. S.; GOMES, A. S.; BRITO, J. A. Estratégias para blended learning na disciplina resistência dos materiais. In: CONGRESSO BRASILEIRO DE EDUCAÇÃO EM ENGENHARIA (COBENGE), 41., 2013, Gramado. Anais... Gramado: UFRGS, 2013.

SILVA, P. F.; MENEZES, C. S. de; FAGUNDES, L. da C. Aprendizagem colaborativa: desenvolvimento de projetos de aprendizagem em ambiente digitais. In: CONGRESSO BRASILEIRO DE INFORMÁTICA NA EDUCAÇÃO (CBIE2016), 5.; WORKSHOP EM INFORMÁTICA NA EDUCAÇÃO (WIE), 22., 2016, Uberlândia. Anais... Uberlândia: UFU, 2016. p. 815-824.

VALENTE, J. A. Blended learning e as mudanças no Ensino Superior: a proposta da sala de aula invertida. Educar em Revista, Curitiba, n. 4, p. 79-97, 2014. Disponível em: $<$ http://www.scielo.br/scielo.php?script=sci_arttext\&pid=S0104$-40602014000800079 \& \operatorname{lng}=e n \& n r m=i s o>$. Acesso em: 13 ago. 2017. 
